\title{
ANÁLISE DA EFICIÊNCIA MUNICIPAL EM GASTO COM EDUCAÇÃ̃o NOS MUNICÍPIOS BAIANOS
}

\author{
Henrique Zardo Motté1, Cleiton Silva de Jesus ${ }^{2}$
}

1. Bolsista FAPESB, graduando em Economia, Universidade Estadual de Feira de Santana, email: henriquezardomotte@gmail.com

2. Orientador, Departamento de Ciências Sociais Aplicadas, Universidade Estadual de Feira de Santana, email: cleiton.uefs@gmail.com

PALAVRAS-CHAVE: Finanças Públicas; Educação; DEA.

\section{INTRODUÇÃO}

Nas últimas décadas, o investimento em educação e seus benefícios têm sido amplamente discutidos na literatura econômica. De um modo geral as nações que investiram maciçamente em educação obtiveram maiores taxas de crescimento econômico. Porém, aumentar o gasto em educação não é condição suficiente garantir êxito em termos de crescimento e desenvolvimento. É preciso também que o investimento seja aplicado de forma eficiente para minimizar os desperdícios e maximizar os ganhos na qualidade do ensino. (ALMEIDA e GASPARINI, 2011)

A responsabilidade sobre a educação brasileira foi descentralizada entre seus entes federativos com a constituição de 1988 e, principalmente, a partir de 1996 com a Lei de Diretrizes e Bases da Educação. Com os estados e os municípios participando ativamente das decisões, as políticas educacionais se tornaram bastante heterogêneas. Faz-se necessário, portanto, criar medidas que avaliem a eficiência dessas políticas e a qualidade do ensino público com o objetivo de indicar as unidades que dispõem das melhores práticas educacionais e utilizar estes modelos como benchmark para as demais.

Trabalhos como o de Jacob Mincer (1974) mostram que indivíduos mais escolarizados recebem maiores salários. Todavia, existem evidências empíricas de que os ganhos sociais são ainda maiores que o retorno privado (GLAESER, 1999; GLAESER e MARE, 2001; ROCHA et al, 2013; MORETTI, 2004; RAUCH, 1993). Esses estudos mostram que, mesmo controlando as características individuais, regiões com maiores estoques de capital humano estão associadas a um nível de renda mais elevado. Outros estudos se propõem a examinar a relação entre a educação e aspectos sociais como benefícios na saúde (JANET CURRIE e MORETTI 2003; SANTOS e KASSOUF, 2007) e redução da criminalidade (LOCHNER e MORETTI, 2004; KUME, 2004).

Há algum tempo a educação tem sido inserida também nos modelos de crescimento econômico (MANKIW, ROMER e WEIL, 1992) e muitos trabalhos já apontaram sua forte correlação com o aumento do produto (BARRO e LEE, 1993; BARRO e LEE, 2010). Porém, além da quantidade, a literatura vem cada vez mais se preocupando em incluir a qualidade do ensino nos modelos de crescimento econômico (AMARAL e MENEZES-FILHO, 2008; HANUSHEK e WOESSMANN, 2012; HANUSHEK e KIMKO, 2000).

Entender a importância da qualidade do ensino é bastante intuitivo. Contudo, parte majoritária dos trabalhos em educação ainda hoje encara um ano de estudo, independente da instituição onde se tenha estudado, como capaz de gerar impactos semelhantes nas variáveis socioeconômicas. Apesar da robustez destas análises, esta é uma hipótese que muitas vezes 
parece forte, dada a heterogeneidade da oferta de educação entre os diversos municípios e/ou escolas.

A literatura econômica vem, portanto, cada vez mais se preocupando em analisar os efeitos dos diferenciais de qualidade na dimensão dos impactos da educação. Os resultados têm corroborado com a intuição, a qualidade é essencial para que os investimentos em educação obtenham os efeitos desejados (HANUSHEK e WOESSMANN, 2012; HANUSHEK e KIMKO, 2000). Ou seja, é importante que o aluno permaneça um maior tempo na escola, mas é imprescindível que isso represente uma melhora efetiva de suas habilidades cognitivas e não um simples dado estatístico.

Deste modo, o estudo a ser realizado pretende avaliar a eficiência dos municípios baianos no gasto púbico com educação. Isto é, avaliar quais os municípios que conseguem obter melhores resultados, dado os recursos disponíveis. Para isso, a metodologia escolhida foi a Análise Envoltória de Dados (DEA), por permitir construir um indicador de eficiência para cada município, o que possibilitará realizar uma comparação entre os diversos municípios baianos.

\section{METODOLOGIA}

Este artigo se baseia na hipótese de que, como está disponível na literatura, a simples análise quantitativa dos gastos em educação não é suficiente para explicar os diferenciais de qualidade no ensino. Porém, maiores níveis de eficiência nos investimentos feitos nessa área estão diretamente relacionados à melhores resultados.

Como o objetivo central do trabalho consiste em avaliar a qualidade dos gastos em educação dos municípios baianos, foi adotada a metodologia de Analise Envoltória de Dados (DEA), muito utilizada para avaliação de políticas públicas. Essa técnica tem como objeto de análise unidades tomadoras de decisão (DMUs), sendo estas instituições públicas, indústrias ou qualquer outra entidade que objetive transformar insumos (inputs) em produtos (outputs).

Muitos trabalhos já utilizaram a mesma metodologia para avaliar a capacidade das instituições públicas em transformar seus recursos em resultados efetivos. Um exemplo é Almeida e Gasparini (2011) que, em trabalho com objetivo semelhante a este, utilizaram a metodologia DEA para medir a eficiência dos gastos públicos em educação nos municípios da Paraíba. Já em Faria et al. (2008) a mesma metodologia é aplicada para avaliar os gastos em educação e saúde nos municípios do Rio de Janeiro.

A metodologia DEA utiliza da programação matemática para construir uma fronteira de eficiência sem que seja necessário estimar uma função de produção. Dessa forma é possível obter o grau de eficiência das unidades comparando a distância de cada DMU com sua respectiva projeção na fronteira. Vale ressaltar, contudo, que a eficiência calculada pelo método é relativa, possibilitando comparações apenas entre as unidades presentes na amostra.

\section{RESULTADOS}

Alguns municípios não puderam ser analisados por indisponibilidade dos dados, com destaque para alguns municípios de médio porte como Alagoinhas, Itabuna, Ilhéus e Eunápolis. Foi gerado, portanto, um índice de eficiência nos gastos em educação para 367 municípios baianos. Tendo em vista o número elevado de municípios, serão apresentados em tabela apenas aqueles que obtiveram os melhores resultados no índice, assim como os que se destacaram negativamente. 
Municípios mais eficientes

\begin{tabular}{|c|c|c|c|c|c|r|}
\hline Município & MATEMÁTICA & PORTUGUÊS & IDEB & \multicolumn{3}{c|}{ PROJEÇ̃̃o Despesa/Matrícula índice DEA } \\
\hline Itapetinga & 196 & 182 & 4,4 & 3,7 & 2107 & 1,00 \\
\hline Licínio de Almeida & 229 & 206 & 5,8 & 4,7 & 3322 & 1,00 \\
\hline Malhada de Pedras & 239 & 225 & 5,9 & 3,5 & 5023 & 1,00 \\
\hline Itapitanga & 239 & 205 & 4,7 & 3,7 & 3899 & 1,00 \\
\hline Salvador & 193 & 178 & 4,0 & 3,9 & 2201 & 0,97 \\
\hline Piatã & 226 & 202 & 5,5 & 4,3 & 3864 & 0,96 \\
\hline Brumado & 226 & 211 & 5,6 & 4,2 & 4526 & 0,96 \\
\hline Jacaraci & 225 & 209 & 5,5 & 4,9 & 4517 & 0,95 \\
\hline Caculé & 227 & 199 & 5,6 & 4,9 & 4153 & 0,95 \\
\hline Guajeru & 214 & 203 & 4,9 & 4,1 & 3767 & 0,94 \\
\hline
\end{tabular}

Municípios menos eficientes.

\begin{tabular}{|c|r|r|r|r|r|r|}
\hline CIDADE & MATEMÁTICA & PORTUGUÊS & \multicolumn{5}{c|}{ IDEB } & \multicolumn{5}{r|}{ PROJEC̃ÃO Despesa/Matricula Índice DEA } \\
\hline Itaquara & 154,87 & 144,07 & 3,2 & 3,5 & 4217,142182 & 0,66 \\
\hline Santo Estêvão & 152,55 & 142,55 & 2,9 & 3,7 & 4076,227847 & 0,66 \\
\hline Sítio do Mato & 150,96 & 136,52 & 3,1 & 3,2 & 3422,330893 & 0,66 \\
\hline Buerarema & 157,87 & 146,53 & 2,8 & 3,8 & 5326,16273 & 0,66 \\
\hline Ruy Barbosa & 153,62 & 140,62 & 3,1 & 3,9 & 4158,749733 & 0,66 \\
\hline Santa Luz & 152,04 & 147,06 & 3,3 & 3,7 & 4606,294027 & 0,65 \\
\hline Ponto Novo & 155,88 & 145,27 & 3,0 & 3,8 & 5337,280353 & 0,65 \\
\hline Jaguaripe & 158,63 & 142,09 & 2,8 & 3,9 & 5397,261095 & 0,65 \\
\hline Almadina & 153,69 & 147,00 & 3,2 & 3,9 & 5371,207911 & 0,65 \\
\hline Manoel Vitorino & 138,23 & 133,03 & 2,6 & 3,5 & 4334,017472 & 0,60 \\
\hline
\end{tabular}

\section{CONSIDERAÇÕES FINAIS}

No presente trabalho foram calculados índices de eficiência para o gasto público em educação nos municípios baianos. Para construção deste indicador a metodologia adotada foi a Análise Envoltória de Dados (DEA). É importante ressaltar que o DEA se limita a construir o indicador de eficiência, não sendo possível, portanto, identificar os motivos que levam determinado município a obter maior ou menor grau de eficiência. Tais motivos podem estar diretamente relacionados à gestão das instituições de ensino, à qualificação dos professores e à estrutura disponível aos alunos. Contudo, fatores externos também podem estar relacionados à eficiência dos gastos como o nível de instrução dos pais e a habilidade natural desses estudantes.

Em uma amostra contendo um número tão elevado de observações e de características tão heterogêneas, avaliou-se que a tentativa de inserir outros insumos que não fossem a despesa com educação poderia beneficiar ou prejudicar determinadas DMUs, além de fugir do objetivo deste artigo que é medir a eficiência dos gastos. Dessa forma, é mais interessante que a elaboração da justificativa para cada município obter sua respectiva taxa de eficiência seja feita de forma mais particularizada, para não causar prejuízos ao modelo.

Os municípios de Itapetinga, Licínio de Almeida, Malhada de Pedras e Itapitanga foram considerados $100 \%$ eficientes em relação aos demais municípios. Salvador, a capital baiana, se mostrou quase totalmente eficiente, com um elevado índice de $97 \%$ de eficiência calculado pelo DEA. Feira de Santana e Vitória da Conquista, duas grandes cidades da Bahia, 
tiveram resultados inferiores e por isso não foram incluídas na tabela, seus índices foram de respectivamente $76 \%$ e $85 \%$ de eficiência.

O cálculo do índice de eficiência não tem a intenção de avaliar quais municípios possuem um sistema educacional mais desenvolvido. O intuito principal é verificar onde se consegue obter melhores resultados dado os recursos disponíveis, ou seja, onde o poder público consegue transformar melhor seus investimentos em qualidade de ensino. Podemos então verificar que os municípios que tiveram um elevado nível de eficiência conseguiram superar as projeções para seus Índices de Desenvolvimento da Educação Básica (Ideb). O inverso acontece com os municípios menos eficientes, estes apresentaram Ideb inferior à projeção.

\section{REFERÊNCIAS}

ALMEIDA, A, T, C.; GASPARINI, C, E. Gastos Públicos Municipais E Educação Fundamental Na Paraíba. Revista Econômica Do Nordeste. Volume 42, N03, Julho-Setembro, 2011.

BARRO, RJ \& LEE, J-W (2010) A new data set of educational attainment in the world, 1950-2010: NBER Working Paper No. 15902. The National Bureau of Economic Research.

BARRO, R.J. \& J.W. LEE. 1993. "International Comparisons of Educational Attainment," Journal of Monetary Economics, 32, 363-94

HANUSHEK, E. A., \& KIMKO, D. D. (2000). Schooling, labor force quality, and the growth of nations. American Economic Review, 90(5), 1184-1208

HANUSHEK, E. A. \& L. WOESSMANN. Schooling, educational achievement, and the Latin American growth puzzle. J. Development Economics 99 (Nov/2012), 497-512, Elsevier.

MANKIW, N. G., ROMER, D., \& WEIL, D. M. (1992). A Contribution To The Empirics Economic Growth. Quarterly Journal Of Economics, 107(2):407-437.

MENEZES-FILHO, N.; AMARAL, L. (2008) A Relação entre gastos educacionais e desempenho escolar. Anpec, XXXVI Encontro Nacional de Economia.

MORETTI, E. "Estimating The Social Return To Higher Education: Evidence From Longitudinal And Repeated Cross-Sectional Data". Journal Of Econometrics, N.121, P.175212, Jul.-Ago.,2004.

ROCHA, R. M. ; SILVEIRA NETO, Raul M. ; GOMES, S. M. F. P. O. ; Coelho Junior, A. F. . Externalidades Do Capital Humano: Uma Análise Empírica Para As Cidades Brasileiras. In: 41 o Encontro Nacional De Economia, 2013, Foz Do Iguaçu. Anais Do 4lo Encontro Nacional De Economia, 2013.

KUME, L. Uma estimativa dos determinantes da taxa de criminalidade brasileira: uma aplicação em painel dinâmico. In: Encontro Nacional de Economia (ANPEC), XXXII, 2004, João Pessoa-PB. Anais eletrônicos

CURRIE, JANET, AND ENRICO MORETTI. 2003. "Mother's Education and the Intergenerational Transmission of Human Capital: Evidence from College Openings." Quarterly Journal of Economics, 118(4): 1495-1532.

FARIA F. P.; Jannuzzi P. M.; Silva S. J. Eficiência dos gastos municipais em saúde e educação: uma investigação através da análise envoltória no estado do Rio de Janeiro. Revista de Administração Pública RAP — RIO DE JANEIRO 42(1):155-177, JAN./FEV. 2008. 